\title{
$\$$ Research Square

\section{Parents as carers on a neonatal unit: qualitative study of parental and staff perceptions in a low-income setting}

\section{Sokhna Ndiaye}

London School of Hygiene and Tropical Medicine

Johanna Bosowski

London School of Hygiene and Tropical Medicine

Lisine Tuyisenge

University Teaching Hospital of Kigali

\section{Loveday Penn-Kekana}

London School of Hygiene and Tropical Medicine

\section{Sarah Moxon}

London School of Hygiene and Tropical Medicine

Nicki Thorogood

London School of Hygiene and Tropical Mecine

Thomas Lissauer ( $\boldsymbol{\nabla}$ t.lissauer@imperial.ac.uk)

Imperial College Healthcare NHS Trust https://orcid.org/0000-0003-0352-1111

\section{Research article}

Keywords: Newborn, family-centred care, neonatal unit, Rwanda

Posted Date: July 1st, 2019

DOl: https://doi.org/10.21203/rs.2.10789/v1

License: () (i) This work is licensed under a Creative Commons Attribution 4.0 International License. Read Full License

Version of Record: A version of this preprint was published at Early Human Development on June 1st, 2020. See the published version at https://doi.org/10.1016/j.earlhumdev.2020.105038. 


\section{Abstract}

Background. To determine parents' experiences on a neonatal unit in a low-income country, how they and staff perceive the role of parents and if parent's role as primary carers could be extended. Methods.

Qualitative analysis using semi-structured interviews with 12 parents and 16 staff. Results. Parental themes were around their general impression, stress and discharge. They were satisfied with their baby's care but feared their baby may die. Mothers were stressed from need to remain in the hospital throughout baby's stay, to provide feeds day and night, comfort and clean their baby, and provide constant kangaroo mother care before discharge. They experienced loneliness from lack of visitors, difficulty finding food and somewhere to sleep, financial worries and concern about family and home. Mothers were desperate to be discharged. Staff were preoccupied with shortage of nurses limiting care provision and restricting their ability to educate parents as inpatients and after discharge and to provide follow-up, and their constant presence. Neither thought parent's role could be extended. Conclusion. Staff and parent perceptions on improving parent's experience differed. Staff thought that the solution was increasing nurse numbers to improve care and educate parents, but is unlikely in near future. Parents were severely stressed by psychosocial concerns and practical issues around hospitalization. Our identification of parental concerns suggests greatest potential for improving their stay on the neonatal unit may be from psychosocial support, potentially from experienced mothers, mothers' groups, allied health professionals and community health workers and from improved facilities, particularly providing food and accommodation.

\section{Background}

The central role of parents of babies on neonatal units is the cornerstone of family centred care ${ }^{1}$. It is a guiding principle in the WHO Survive and Thrive Framework for Nurturing Care for Early Childhood Development, in recognition of the benefits of close caregiver-child interactions on the development of young children $^{2}$. This has been extended in family integrated care, where parents become the primary caregivers $3,4,5$. These models of care have drawn on practices developed in low and middle-income countries, where parents tube or cup-feed and change and clean their preterm or sick babies to alleviate staff shortages and provide prolonged skin-to-skin care as Kangaroo Mother Care (KMC) ${ }^{6,7}$.

The aim of this study was to determine parents' experiences, how they and staff perceive parents' role to determine if parents' role as primary carers could be extended in a neonatal unit in a low-income country, Rwanda.

In Rwanda, it is the norm for mothers of newborn babies, even if admitted to a neonatal unit, to stay with them in hospital until discharged home. Rwanda has achieved a marked reduction of neonatal mortality rate since the genocide in 1994 and reached 17 per 1000 live births in $2016^{8}$. Over $90 \%$ of births are now in hospitals or health centers ${ }^{8}$. A major neonatal improvement program to achieve the UN Sustainable Development Goal target of 12 per 1,000 live births by 2030 is being undertaken ${ }^{9}$. However, a major impediment is a severe shortage of trained healthcare professionals ${ }^{8}$. 
The study was conducted at Nyamata Hospital, a busy rural, district hospital, serving a population of 421,000 people where the senior author has a working relationship. There are approximately 4000 hospital and 10,000 health center deliveries every year. There is a single neonatal unit serving the district, with 800 admissions per year. Mortality is $15-18 \%$ of admissions, which is above the national average ${ }^{9}$. It has 30 beds, with 10 incubators and 15 cots and a "KMC (Kangaroo Mother Care) room" with 6 beds for KMC mothers and 5 for mothers of babies in the unit. The unit is staffed by a total of nine nurses, but three were on long-term leave during the study. There were 2 nurses on duty during the day, 1 at night, supplemented by student nurses. There was 1 pediatrician for both the neonatal unit and general pediatrics. Other medical care was provided by junior doctors who also covered other specialties. Respiratory support was provided with CPAP (continuous positive airway pressure), and wall oxygen and vital sign and oxygen saturation monitoring were available. There was no provision for milk storage or running water, but water was provided from tanks and alcohol gel was available. Babies were transferred to KMC when they no longer required oxygen therapy, intravenous medications or nasogastric feeding and were gaining weight.

\section{Methods}

All parents on the unit during the study period were invited to be interviewed. The aim was to interview a minimum of 10 parents. Interviews were to be conducted outside the neonatal unit to preserve privacy and confidentiality. Interviews were arranged opportunistically. Staff who worked in or supervised the unit were also interviewed, with the aim to again conduct a minimum of 10 interviews. An interpreter assisted with translation in some interviews. A semi-structured questionnaire was developed with input from doctors and nurses working in Rwanda. Interviews were audio-recorded and later transcribed and translated when necessary. Fieldnotes were also kept. Thematic content analysis was performed with a combination of deductive and inductive codes being developed ${ }^{11,12}$. A selection of interviews were independently coded by two experienced academic staff and differences discussed as a team.

Ethical approval was obtained from the Rwanda National Ethics Committee, the Rwandan National Health Research Committee of the Ministry of Health, and the London School of Hygiene and Tropical Medicine's Ethics Board. Written informed consent was obtained from all participants.

\section{Results}

Interviews were conducted with 10 mothers and 2 fathers, and lasted 27 to 65 minutes. Eight of the mothers delivered at the hospital and two at health centers.

Sixteen staff interviews were undertaken; 4 doctors, 7 nurses, 3 cleaners and 2 allied health professionals.

\section{Thematic analysis}

Themes identified from parental interviews were their general impression and their severe stress. From staff interviews, themes that emerged were inadequate nurse staffing, their role as a constant presence and 
educators. Discharge home was a major concern for both. Both groups were asked about their attitude to performing additional tasks.

\section{Parental interviews}

\section{General impressions}

Almost all of the mothers expressed favorable views, "My impression was good because I find that the staff here really takes care of the babies." Nine of the ten participants stated the medical staff provided proper care for their babies. Even a mother who had lost her baby the night before, said: "Any child that dies, it is not because nothing was done, but because he was destined to die because they gave everything that needed to be given to my baby. I would tell a future mother to hurry up and bring her baby here because there is real rescuing here." Mothers said they placed all hope in God, and trusted the medical team.

In relation to the mother's perception of their role in the neonatal unit, feeding was seen as a major role. " $M y$ day is filled with breastfeeding from morning to night, that's what I do." 'There is breastfeeding every 3 hours, changing his clothes when he has peed or pooped and laundry to clean the baby's clothes to avoid infections.'Some of the mothers were also feeding via a nasogastric tube.

Although visiting rights were fully granted to mothers, it seemed restrictions applied to others. One mother testified "for the baby's mother, yes, she can stay as long as she wants. They don't refuse for the father; however, they don't accept that he stays too long. But when visitors come, then it's complicated. They don't want them to come or stay long." On father reported "It is not allowed to stay long because we prevent the babies from breathing. We consume their air."

\section{Communication}

Only $30 \%$ of the mothers had an introductory tour of the unit; one mother said "Yes, I would have wanted that but I ended up doing the tour all alone". Only 30\% were told how to produce breastmilk and maintain their baby's hygiene; the remainder said they were given no instructions.

Mothers reported issues with the level of communication with health care workers. Seven of the mothers said they had not been informed what was wrong with their baby and none said that they knew what treatment their baby was receiving. Only half reported being told about their baby's current health once or twice a day. Mothers felt it was challenging to ask for information, although many reported that it was easier to talk to the pediatrician when she did her rounds. This was also observed by the researchers.

Four of the mothers were providing intermittent KMC, but none had its purpose explained by a health professional. One hypothesized "the baby gains in warmth and weight", another "maybe she could, then, breathe well" and another mother said "when the mother's heart beats it helps the baby feel better".

\section{Maternal stress}

High levels of stress and anxiety were reported by all the mothers. A range of factors contributed to these feelings. 
i) Fear of their baby dying. Mothers reported being extremely anxious about the possibility of their baby dying. "What worries me the most is to see some deaths around here. I know that maybe the next baby could be mine". During this study, 4 babies died. Prior to this hospitalization, 3 mothers had personally experienced loss of a child.

Oxygen therapy was associated by some of the mother's with death. A mother described her most distressing moment, "I could only be worried because from the moment the baby was placed on oxygen, I was afraid, I told myself that maybe things were not going well. [...] That she could die." Faith and belief in God helped mothers cope and maintain hope. One declared: "I can only praise God because my baby that is still alive has nothing special that the other one doesn't have".

ii) Concern about their own health. Some of the mothers had concerns about their own health. "What worries me the most is my own health. I have had surgery, and the after-surgery is still painful". This was an issue particularly if they were not well enough to go to the neonatal unit after the delivery. A mother who was hospitalized in maternity for 24 hours reported that this meant her baby had not been fed. They expressed concern that unless they were present in the neonatal unit their baby was not fed and they were not informed about their baby's wellbeing.

iii) Isolation and loneliness. Long travel distance of 1 to 5 hours or expense limited visits by family members. Only 2 fathers visited, 7 others were reported to be unable to come as they were needed at home. "Because of poverty, my husband cannot find the ticket (transportation fare) to come visit me every day. My father is too old to move around. My mother is no longer." Another mother said "I am not married. I had the baby with a man who disappeared. My first baby's father is in jail. I came here alone, my parents have died."

iv) Meeting their own needs. Obtaining food was a major source of anxiety for most of the mothers, as no food is provided and shops are some distance away. "We have to fight to find food". "Some mothers do not have families who can bring them food. It's really hard to cope around here."

They also complained that whilst their baby was in the neonatal unit there was often insufficient place to rest and sleep at night, and insufficient bedding, so they just had to find somewhere in the hospital to sleep. There was also a lack of facilities to eat and store things, and no clothes lines to hang their baby's clothes.

v) Financial worries. Fear of hospital bills was a big worry "as a poor person my worry is how I will pay the medical expenses for my baby. [...] I know it is cheaper with the mutuelle (health insurance) paying most of the costs, but it also depends on how long you stay."

vi) Mental health. When asked what helped them cope, the majority of mothers responded that it was the attention staff gave to their baby or assurance when seeing their baby improving. They also reported good collaboration with other mothers. They lent each other basins, shared food and water (for washing), and helped each other cope.

However, some concerning behaviors regarding mental health were observed on the unit. Several mothers displayed expressions of deep sadness, looking lost in deep thought, isolation and apathy. One mother was 
observed to handle her baby inappropriately. One of the fathers commented "there should be a team to comfort mothers because many of them arrive depressed and they don't know how to pick themselves up."

\section{Staff perspective}

Inadequate nurse staffing. This was perceived as the central issue by all the staff, and the reason for the nurses being unable to provide the care they would like. During the study period the bed to nurse ratio varied from 7:1 to 31:1. There was a focus on technical tasks and some staff acknowledged their neglect of parents' needs. "Because of many patients, one nurse, so there are some practices that we don't do because we are overwhelmed, so sometimes we don't do".

Role of nurses. A strong theme around the role of the nurse was that they are a constant presence, everwatchful and vigilant at the side of the patient. This contrasted with the doctors who were perceived as transient, "doctors they are just seeing the baby, writing what to do and then they leave, so, because nurses are there from the first minute to the last minute, the first person who is important for babies... to be alive, or to becoming in good life is nurses".

The importance of the mother's presence for her baby was generally recognised by nurses. "Mothers are most of the time here. We need them... we are giving treatment...but they are bathing them, they do hygiene for them... In feeding also... they are helping".

However, the necessity of the mothers participating in the care of the babies was not viewed as entirely beneficial, because of the need to protect the babies from outside infection. Visitors were viewed by some staff as a source of infection, and sometimes not allowed in the unit.

The role of staff as educators of 'correct' ways of caring was emphasised as a way of protecting babies throughout their hospital stay and after discharge. "Fighting hypothermia, feeding on time, giving the right dose of medication at the right time, that's what we need. And, it's the role of the nurse". There was strong mistrust by staff of "traditional ways" of caring for babies, as learnt from family or community. "It's the role of the nurse to educate the mother how to take care of the baby".

Education was also seen as important so that staff avoided blame if the baby died. Frontline participants described their emotional toll when a baby died, but emphasised the importance of overcoming their feelings to be professional, "we try to talk to the mother before the death, so the mother knows we are trying our best. And after death would not blame anybody. Say well they tried their best, so we have not to blame them".

\section{Potential extension of parent's role}

The possible extension of mothers' role in caring for their babies was explored with both parents and staff.

The majority of mothers doubted their ability to perform clinical tasks because they believed their social role/status did not provide them with the level of literacy and training required. When asked if she would take her baby's temperature, one mother said "No. The nurse does that. If I am not taught how to do it, I don't see how I would be able to. For those who are illiterate, it could be difficult." 
Overall, mothers preferred not to be asked to perform activities that they perceived as the tasks of nurses, especially recording results involving writing, because they were already tired, preoccupied with other things, and not trained. One explained "we have many things on our mind, many problems, especially thinking about things at home or family problems, then sometimes it is difficult to do some activities that we are asked to. However, when we are free and relaxed, then, we can do it".

Staff differed in their opinions as to whether parental participation was desirable or whether it was a way of dealing with staff shortages. Staff perceived that mothers understood the benefits of KMC and enjoyed practicing it, but its implementation was difficult because of competing demands on the mothers' time. "It's not easy because sometimes they don't have any help, sometimes she has to leave the baby for cooking, seeking food, and laundry, so it's not always possible to have twenty-four hours with them.

\section{Concern about care after discharge}

A contrast emerged between the staff's way of looking after babies, compared to the care that babies would receive at home. Mothers trusted the staff to care for their babies, but staff were concerned that mothers could not provide the care their babies needed. "People from the community don't know how to care for the babies, but, if you are educating more and more they can know how to keep their babies in good health" ."When a baby is discharged home mothers don't care of them as well as in hospital... and once discharged they, start... to do other things, look for food, and so on, so the baby can be sick again and can come back to hospital because of lack of appropriate care. So, we should do more than we do now, and follow those babies at home and see how they are".

\section{Discussion}

This is one of the few studies that has analysed both parent's and staff's perspective on the experience of having a baby on a neonatal unit in a low-income country. Parents reported that they felt that the medical care provided was satisfactory and that they would recommend the unit to others. A recent upgrade of the unit, with a range of modern equipment, expansion of KMC facilities and intensive training of staff for 6 months by a pediatric doctor and nurse from the UK may have improved their experience of the unit. Their fear of their baby dying reflects the reality of the relatively high mortality of admitted babies.

The expectation that mothers stay in the hospital until their baby goes home, means they fully feed and care for their babies even whilst their baby receives medical care. However, our study shows that this created considerable stress, especially if unwell or in pain, as they needed to be present to feed regularly day and night, as there was no milk storage. Loneliness and isolation were exacerbated by this being a poor, rural location, where long journeys and expense made it more difficult for family members to visit. This contrasted with a study on acceptability of family-centered care in Delhi in India, where considerable support was provided by the extended family ${ }^{13}$. All mothers complained about difficulty in obtaining and preparing food, which is not provided for mothers or patients in Rwanda. Although most babies' basic hospital costs are covered by the local insurance scheme, ("the mutuelle"), a 10\% contribution must be made, so additional cost is accrued for each hospital day. Monetary worries, and concern about their families, made mothers desperate to get home. 
Staff were preoccupied with shortage of nurses and their inability to provide proper care for the babies receiving technical support. Inadequate staff supervision of parents was problematic, particularly during $\mathrm{KMC}$. It also meant that KMC was viewed as a separate entity practiced in a step-down unit prior to discharge instead of a continuous care practice starting at birth ${ }^{14}$.

The nurses considered themselves able to provide the care, supervision, education and emotional support the parents needed, but were hampered by insufficient staff numbers. They acknowledged they did not have adequate time to educate mothers about care following discharge. This concern is substantiated by a followup study of babies from a neonatal unit in Rwanda, which found that amongst the survivors at 22 months post discharge, $46 \%$ had feeding difficulties, $78 \%$ were stunted, $9 \%$ were wasted and $67 \%$ had abnormal developmental screening ${ }^{15}$.

Neither parents nor staff thought that the role of parent's should be extended as parents already participated extensively in the provision of their baby's care, would require additional education and training of mothers and everyone was already overcommitted.

As raised repeatedly by all staff, nursing numbers need to be increased, but a marked increase is unlikely soon as neither funding nor qualified nurses are available. In addition, analysis of the way nurses allocate their time in several neonatal units in Kenya showed that they undertook "subconscious triage", delegating non-clinical tasks to support staff and parents. This was at the expense of holistic, personal bedside care which only occurred while nurses were en-route to attending sick babies and performing technical tasks ${ }^{16}$. This suggests extra time created by an increase in nursing numbers would not necessarily be allocated to the needs of parents.

As additional nursing staff are unlikely in the near future, a way to address the issues and concerns expressed by the parents is to explore assistance from non-clinicians and allied health professionals. Experienced or "veteran" mothers ${ }^{17}$ and allied health professionals such as social workers or clinical psychologists may be beneficial in providing psychosocial support and in improving the care provided in the neonatal unit including KMC and discharge preparation. Women's and parent support groups have shown that peer-to-peer support rather than education by health professionals is particularly helpful ${ }^{18}$. Videos and mobile phone apps addressing parental issues in local languages may be additional aids, and some are already available (in Kinyarwanda in Rwanda ${ }^{19}$ ). Developing close links with community health workers is likely to be advantagous ${ }^{20}$; an extensive network of volunteer community health workers has been developed in Rwanda, though additional training in the care of the preterm or ill infants graduating from the neonatal unit may be beneficial.

\section{Limitations}

A limitation of this study is the relatively small number of parents and staff interviewed. Obtaining informed consent was time-consuming and some declined to continue, although the target number of interviews was achieved. Participation may have been reduced by not providing any incentives, neither financial nor as gifts, to take part, and the need for a translator prolonged the interview. There may have been reluctance by some parents to be critical for fear of jeopardising their baby's care or of reprisal, in spite of assurance that the 
researchers were independent. Although mothers described being stressed and anxious, their levels of stress or anxiety were not formally measured.

\section{Conclusions}

This study revealed a marked difference in staff and patient perception on how to improve parents' experience. The focus of governments and outside agencies in low and middle-income countries has been to reduce neonatal mortality, and its reduction in Rwanda has been remarkable. The pressure for further reduction together with the severe shortage of nursing staff on the neonatal unit, with observed bed to nurse ratio varying from $7: 1$ to as much as $31: 1$, was reflected in the preoccupation of staff on the need to increase the number of trained health professionals. The staff thought that the way to improve parent experience was also primarily through having more nurses and that this would enable them to provide more parent education on the unit and preparation for discharge.

Mothers reported feeling stressed from the constant need to provide feeding and care day and night, fear for their baby's survival, concern about their own health and family at home and practical issues around hospitalization, particularly isolation and loneliness, obtaining food, sometimes finding somewhere to sleep, lack of utensils and clothes-lines and hospital fees. Concerning behaviour relating to some mother's mental health was also observed. Alleviating these issues suggests a need to provide psychosocial support and help to provide the practical issues identified. Under current circumstances, both nurses and parents were reluctant to consider extending the clinical role of parents, as in family integrated care, as both groups were preoccupied by more immediate concerns.

Whilst some of the issues raised, such as lack of provision of food for resident mothers, may be local, many will be widely applicable to other neonatal units in low and middle-income countries.

\section{Declarations}

\section{Acknowledgements}

We would like to thank the parents and staff who agreed to be interviewed and be part of this study and the Hospital Director at Nyamata Hospital for allowing this study to be undertaken. We would also like to acknowledge the assistance received from Dr Alice Wilson and Sarah McMurtrie who spent six months at the hospital with the Royal College of Paediatrics and Child Health Neonatal Program enthusiastically contributing to the improvement program prior to this project, and provided us with advice and local feedback of the semi-structured questionnaire used for the interviews. We would also like to thank Dr Jay Banerjee, Consultant Neonatologist at Imperial College Healthcare Trust for his advice and encouragement and review of the manuscript.

\section{Funding}

Assistance with travel expenses was received from the LSHTM Travel Scholarships Fund.

\section{Availability of data and materials}


All data was anonymized when transcribed.

\section{Author's contributions.}

The corresponding author TL devised and oversaw the study and drafted the paper. SN and JB conducted interviews of parents and staff respectively and undertook the qualitative analysis under the guidance and supervision of L P-K, NT and SM. L P-K and SM organized the project in the UK, LT organized the project in Rwanda. All the authors read and approved the manuscript.

\section{Ethics approval and consent to participate}

Ethical approval was obtained from the Rwanda National Ethics Committee (FWA Assurance No 00001973), the Rwandan National Health Research Committee of the Ministry of Health, and the London School of Hygiene and Tropical Medicine's Ethics Board. Participation was entirely voluntary, and explanation provided that interviewers were independent and that any views expressed would be anonymous and they were free to participate or not and could withdraw at any time and their baby's care would not be affected. Written informed consent was obtained from all participants. Interviews were recorded, which was encrypted on a personal password protected phone. The audio files were transferred from the phone to the encrypted hard disk of a password protected computer on the same day. The files were securely deleted from the phone after transfer, and deleted. Pseudonyms were used for names of study participants and any identifying information was anonymised during transcription.

\section{Consent for publication}

Not applicable

\section{Competing interests}

The authors declare they have no competing interests.

\section{References}

1 Gooding JS, Cooper LG, Blaine Al et al. Family Support and Family-Centred Care in the Neonatal Intensive Care Unit: Origins, Advances, Impact. Semin Perinatol 2011;35:20-28

2 WHO: Nurturing Care for Early Childhood Development. A Framework for helping children survive and thrive to transform health and human potential. 2018.

3 Warre R, O'Brien K, Lee SK. Parents as the primary caregivers for their infant in the NICU: benefits and challenges. Neoreviews 2014;15:e472-e477 
4 Patel N, Ballantyne A, Bowker G et al. Family Integrated Care: changing the culture in the neonatal unit. Arch Dis Child 2018; 103: 415-419

5. Roué J-M, Kuhn P, Lopez Maestro M, et al. Eight principles for patient-centred and family-centred care for newborns in the neonatal intensive care unit. Arch Dis Child Fetal Neonatal Ed 2017;102:F364-F368.

6 Bhutta ZA, Khan I, Salat S et al. Reducing length of stay in hospital for very low birthweight infants by involving mothers in a stepdown unit: an experience from Karachi (Pakistan). BMJ 2004;329:1151-5

7 Levin A. The Mother-Infant unit at Tallinn Children's Hospital, Estonia: a truly baby-friendly unit. Birth $1994 ; 21: 39-44$

8. UNICEF Countdown to 2030. http://profiles.countdown2030.org/\#/

9. Ministry of Health, Rwanda

http://www.moh.gov.rw/fileadmin/user_upload/HMIS/2016_Annual_Statistical_booklets_V9_08_03_2018.pdf

10. WHO. The Sustainable Development Goals Report 2018. Available from:

https:www.who.int/sdg/targets/en/

11. Nicholson E, Murphy T, Larkin P et al. Protocol for a thematic synthesis to identify key themes and messages from a palliative care research network. BMC Research Notes; 2016:9(1):478

12. Braun V, Clarke V. What can "thematic analysis" offer health and wellbeing researchers? International Journal of Qualitative Studies on Health and Wellbeing; 2014:9(1)

13. Sarin E, Maria A. Acceptability of a family-centered newborn care model among providers and receivers of care in a Public Health Setting: a qualitative study from India. BMC Health Services Research. 2019, $19: 184$.

doi.org/10.1186/s12913-019-4017-1

14. Hodgins S, Valsangkar B, Patterson J. Caution needed to avoid empty scale-up of Kangaroo Mother Care in low-income settings. J Glob Health. 2018 Jun;8(1):010306. doi: 10.7189/jogh.08.010306.

15. Kirk CM, Uwamungu JC, Wilson K et al. Health, nutrition, and development of children born preterm and low birth weight in rural Rwanda: a cross-sectional study BMC Pediatrics 2017;17:191. DOI 10.1186/s 12887017-0946-1

16. Nzinga J, McKnight J, Jepkosgei et al. Exploring the space for task shifting to support nursing on neonatal wards in Kenyan public hospitals. Human Resources for Health.

2019:https://doi.org/10.1186/s12960-019-0352

17. Macdonell K, Christie K, Robson K, et al. Implementing family-integrated care in the NICU: engaging veteran parents in program design and delivery. Adv Neonatal Care 2013;13:262-9 
18. Hall SL, Ryan DJ, Beatty J, et al. Recommendations for peer-to-peer support for NICU parents. J Perinatol 2015;35 Suppl 1:S9-S13

19. Global Health Media. https://www.youtube.com/user/globalhealthmediaorg/videos

20. Koenraads M, Phuka J, Maleta K et al. Understanding the challenges to caring for low birthweight babies in rural southern Malawi: a qualitative study exploring caregiver and health worker perceptions and experiences. BMJ Glob Health 2017;2:e000301.doi:10.1136/bmjgh-2017-000301 